\title{
O BASQUETE DE RUA NOS ESPAÇOS DE LAZER DA REGIÃO METROPOLITANA DE CAMPINAS
}

\author{
Recebido em: 21/11/2017 \\ Aceito em: 15/08/2018
}

\author{
Douglas Vinicius Carvalho Brasil ${ }^{1}$ \\ Universidade Estadual de Campinas (UNICAMP) \\ Campinas - SP - Brasil \\ Thiago José Leonardi ${ }^{2}$ \\ Centro Universitário Adventista de São Paulo, campus Hortolandia (UNASP - HT) \\ Centro Universitário de Jaguariuna (UNIFAJ) \\ Jaguariúna - SP - Brasil
Alcides José Scaglia ${ }^{3}$
Universidade Estadual de Campinas (UNICAMP)
Limeira - SP - Brasil
Roberto Rodrigues Paes ${ }^{4}$
Universidade Estadual de Campinas (UNICAMP)
Campinas - SP - Brasil

RESUMO: A Pedagogia do Esporte tem como objeto de estudo e intervenção o processo de ensino, vivência, aprendizagem e treinamento do esporte, permitindo assim, compreender o esporte sob diferentes aspectos e manifestações. No presente artigo ${ }^{5}$ buscamos identificar de que forma o Basquetebol é praticado nos espaços de lazer da Região Metropolitana de Campinas, para isso foi realizada pesquisa de campo na qual foram observadas 78 partidas em 5 quadras públicas e/ou de livre acesso. Constatamos que os praticantes não seguem as regras e normas estabelecidas pela Federação Internacional de Basquetebol, os jogos observados possuíam características próprias que variaram de acordo com o número de praticantes, características do local e número de praticantes, logo concluímos que a prática do Basquetebol nesses locais se assemelha a do Streetball praticado nas quadras dos Estados Unidos da América.

\footnotetext{
1 Mestrando em Educação Física na Faculdade de Educação Física da Universidade Estadual de Campinas (UNICAMP) e Membro do Laboratório de Estudos em Pedagogia do Esporte (LEPE).

${ }^{2}$ Professor Doutor no Centro Universitário Adventista de São Paulo, campus Hortolandia (UNASP - HT) e do Centro Universitário de Jaguariuna (UNIFAJ).

${ }^{3}$ Professor Doutor, atualmente é docente na Faculdade de Ciências Aplicadas (FCA) no curso de Ciências do Esporte da UNICAMP, responsável/líder pelas pesquisas do LEPE (Laboratório de Estudos em Pedagogia do Esporte), pesquisador do Ludens - USP e coordenador de Graduação da FCA (UNICAMP).

${ }^{4}$ Professor Doutor, atualmente é docente na Faculdade de Educação Física da Universidade Estadual de Campinas. Lider do Grupo de Estudos em Pedagogia do Esporte (GEPESP).

${ }^{5}$ A pesquisa que gerou o presente artigo contou com apoio do Conselho Nacional de Desenvolvimento Científico e Tecnológico (CNPq).
} 
PALAVRAS CHAVE: Atividades de Lazer. Basquetebol. Esportes.

\section{THE STREET BASKETBALL PRACTICED IN THE LEISURE SPACES OF THE METROPOLITAN REGION OF CAMPINAS}

ABSTRACT: The Pedagogy of Sport has as object of study and intervention the teaching process, experience, learning and training of the sport, thus allowing, to understand the sport under different aspects and manifestations. In this article we try to identify how the Basketball is practiced in leisure facilities in the metropolitan region of Campinas, for it was carried out field research in which were found 78 matches in 5 public courts and / or open access. We found that the practitioners did not follow the rules and regulations established by the International Basketball Federation, the games observed had their own characteristics that varied according to the number of players, characteristics of the place and number of players, so we concluded that the practice of Basketball in these places resembles the Streetball practiced in the courts of the United States of America.

KEYWORDS: Leisure Activities. Basketball. Sports.

\section{Introdução}

O esporte e o lazer ${ }^{6}$ são elementos importantes na configuração da sociedade atual, influenciando a economia, estruturas familiares e administração pública. Dada a sua importância, estes temas vêm sendo abordados de formas distintas por diferentes áreas do conhecimento, inclusive a Educação Física (PIZANI; AMARAL; PAES, 2012).

Segundo Pizani; Amaral e Paes (2012), o esporte enquanto atividade de lazer possui caráter educativo, podendo ser visto como importante meio para a educação e a formação da cidadania. Neste contexto, a Pedagogia do Esporte (GALATTI et al., 2014), pautada nos referenciais: técnico-tático, socioeducativo e histórico-cultural (MACHADO; GALATTI; PAES, 2012; 2014), surge como alternativa para que

\footnotetext{
${ }^{6}$ O lazer compreendido a partir de Marcellino (2007), onde este seria a cultura vivenciada de maneiras diferentes, no tempo livre de obrigações (profissionais, escolares, familiares e sociais), sendo exercida sobre ele, influência da atual estrutura social. Sendo ainda, "portador de um duplo aspecto educativo veículo e objeto de educação" (p. 46-47).
} 
profissionais que trabalhem com esporte em suas diferentes vertentes (alto rendimento, escolar, enquanto lazer, entre outros) e contextos (clubes, projetos sociais, escolas, etc.), possam compreender esse fenômeno sob diferentes aspectos, deste modo contribuindo amplamente para formação do indivíduo com o qual trabalhe, assim permitindo que o mesmo

[...] possa usufruir conhecimentos acerca do tema adquiridos ao longo de sua vida escolar, esportiva ou de atleta profissional, a fim de praticar o esporte com o desempenho mínimo exigido e/ou assistir a espetáculos esportivos com conhecimentos básicos das regras, capacidade de análise de jogadas e postura crítica quanto às atitudes morais dos atletas, técnicos, dirigentes, imprensa e demais envolvidos (GALATTI, 2006, p.30).

Reconhecendo a importância e influência que a Pedagogia do Esporte tem para formação dos indivíduos, os preparando não apenas para que sejam capazes de praticar determinada modalidade esportiva, mas também fornecendo conhecimentos para que possam exercer outros papéis relacionados ao esporte (expectadores, consumidores, técnicos, entre outros), no presente artigo buscaremos compreender e caracterizar o Basquete de Rua por meio do referencial histórico-cultural apresentado por Machado; Galatti e Paes (2012; 2014), para então buscar identificar de que forma ocorre a prática do Basquetebol em espaços de lazer ${ }^{7}$ da Região Metropolitana de Campinas (RMC) fora do contexto competitivo.

\footnotetext{
${ }^{7}$ Espaços de lazer compreendidos por Dumazedier (2008), "um espaço social onde se entabulam relações específicas entre seres, grupos, meios, classes." Espaço esse, determinado "pelas características da população que o utiliza, pelo modo de vida dos diferentes meios sociais que o frequentam", que ainda segundo o autor, ao mesmo tempo deve "respeitar, desenvolver as diversidades culturais destes indivíduos para escapar à uniformização, à padronização, ao tédio social."
} 


\section{Do Basquetebol ao Basquete de Rua}

O referencial histórico-cultural apresentado por Machado; Galatti e Paes, (2012; 2014), busca fortalecer o trato pedagógico trabalhando conhecimentos que caracterizam o esporte como elemento cultural e social, abordando o desenvolvimento histórico das modalidades, evolução das regras, influência da mídia, entre outros. Sendo assim, para compreendermos e buscarmos caracterizar o Basquetebol praticado nas quadras públicas e/ou de livre acesso da Região Metropolitana de Campinas, faz-se necessário buscar identificar a origem dessa modalidade, assim como seu desenvolvimento ao passar dos anos, principalmente fora do contexto formal.

O Basquetebol criado por James Naismith em 1891 (CONFEDERAÇÃO BRASILEIRA DE BASKETBALL, [20--?]; FREITAS, A; VIEIRA, S., 2006), inicialmente foi praticado e difundido principalmente por indivíduos pertencentes às elites econômicas norte-americanas, compostas, sobretudo, pela população de origem europeia e pele branca, sendo assim, à população de classes consideradas inferiores economicamente e os afrodescendentes não tinham acesso aos locais onde se praticava o esporte (SILVA; CORREIA, 2008; CANAN; SILVA 2013). Podemos inferir que a população que não tinha acesso aos locais formais para prática do Basquetebol, passou a pratica-lo em outros contextos como as ruas e parques das cidades, o que como veremos, influenciou o modo como o jogo se desenvolveu nesses locais, originando o que seria chamado posteriormente de Streetball.

Segundo Horn (2014), a origem do Streetball não foi documentada, porém suas raízes estariam nas cidades de Nova York (NY) e Washington localizadas nos Estados Unidos da América (EUA), indo de encontro ao apontado por Garcia e Couliau (2012), que creditam aos nova-iorquinos o fato de terem levado o Basquetebol as ruas, onde 
ganhou estilo próprio na década de 1960, predominando a arte de constranger o adversário através de fintas desconcertantes ou de um toque "artístico" em jogadas como a bandeja.

Entre o fim da década de 1960 e início da década de 1970 em Nova York (NY), em decorrência a exclusão social da população de baixa renda surge o movimento HipHop (OLIVEIRA FILHO, 2006; SILVA; CORREIA, 2008). Segundo um dos entrevistados em (DOIN' IT IN THE PARK, 2012), esse movimento teria crescido nos parques, locais onde teriam surgido às sessões e os jogos de rua. Logo o Basquetebol praticado nesses locais também foi influenciado, o que como apontado em (DOIN' IT IN THE PARK, 2012), gerou uma cultura própria, que fortaleceu o jogo no processo.

Desse Basquetebol praticado nas ruas e quadras públicas, surgiu o termo: Streetball, criado pela sociedade midiática norte americana ao notar algo diferente no Basquetebol praticado nestes locais (ZAMBELLI, 2004).

No Brasil os primeiros registros encontrados referentes ao Streetball/Basquete de $\operatorname{Rua}^{8}$ datam os anos de 1993 e 1994, se tratando de dois eventos realizados respectivamente nos estados: Rio de Janeiro (RJ) e São Paulo (SP). O primeiro trata-se de um torneio intitulado "Adidas Streetball Challenge", realizado no estacionamento do Barrashopping no RJ, foram improvisadas 10 quadras $^{9}$, onde equipes compostas por três jogadores cada, disputaram partidas com duração de 10 minutos ou até que uma das equipes marcasse 20 pontos. Além disso, foram realizadas disputas de arremessos do meio da quadra (one shot challenge) e torneio de enterrada (BASQUETE, 1993). O

\footnotetext{
${ }^{8}$ Nos registros os termos são utilizados como sinônimo, adiante usaremos o termo Streetball para nos referir a pratica norte-americana e Basquete de Rua para nos referir a pratica brasileira.

${ }^{9}$ Os jogos foram disputados usando apenas uma tabela e meia quadra, não fica claro nas reportagens se foram feitas 10 meias quadras, ou 5 quadras inteiras que "divididas" somariam 10 "meia quadras".
} 
segundo registro refere-se a um evento ocorrido em 1994 no Ibirapuera em SP que contou com a presença do ex-atleta da NBA Joe Dumars (ESPORTE, 1994).

Aproximadamente entre o fim da década de 1990 e início dos anos 2000, principalmente por meio de ações da empresa de materiais esportivos AND1, o Streetball passou a ter mais visibilidade e popularidade mundo afora, observando isso, Organizações Não Governamentais (ONGs) como a Central Única das Favelas (CUFA) e a Liga Urbana de Basquete (LUB) passaram a investir nessa prática esportiva no Brasil (OLIVEIRA FILHO, 2006; ATHAYDE, [2011?]).

No ano de 2001, durante o festival de Hip-Hop intitulado "Hutúz Rap Festival" organizado pela CUFA, ocorreram partidas improvisadas de Basquetebol, onde de maneira espontânea praticantes utilizaram uma bola e um cesto de lixo (simulando aro) para jogar algumas partidas no local, assim, segundo Athayde ([2011?]), surgia o conceito do Basquete de Rua nacional ${ }^{10}$, uma variação que transita entre o Basquetebol e o Streetball.

No ano seguinte, a CUFA começaria a institucionalizar a prática do Basquete de Rua, criando o "Hutúz Basquete de Rua", evento que contou com a participação de equipes de diversos estados e cidades brasileiras. Essa competição antecedeu outra criada pela ONG, a "Liga Brasileira de Basquete de Rua" (LIBBRA) que surgiu no ano de 2005, com apoio das Organizações Globo e Eletrobrás (OLIVEIRA FILHO, 2006; ATHAYDE, [2011?]).

Com o passar dos anos a CUFA passou a promover disputas internacionais entre as seleções de Basquete de Rua de diversos países, surgia assim o desafio intitulado

\footnotetext{
10 Para nós, não seria o surgimento do conceito, mas sim de um novo conceito ou uma nova maneira de se praticar Basquete de Rua, já que esse termo já era utilizado desde a década de 1990 no Brasil.
} 
Reis da Rua, a LIBBRA passaria a chamar Liga Internacional de Basquete de Rua ${ }^{11}$ (LIIBRA) (REIS DA RUA, [201-?]).

\section{Como se Prática Streetball e Basquete de Rua, Existem Diferenças? ${ }^{12}$}

Identificado o contexto em que surgiu do Basquetebol, que contribuiu para o surgimento do que seria chamado Streetball e consequentemente Basquete de Rua, mas no que diz respeito à prática desses esportes, como é? Existem diferenças?

Para Silva e Correia (2008), originalmente o Streetball seguiria regras simples e flexíveis, privilegiando a força, ousadia e improvisação, em partidas disputadas por duas equipes compostas por três jogadores cada, em metade de uma quadra de basquetebol, utilizando apenas um aro, ao som da música rap. No entanto, ainda segundo os autores, o número de praticantes de praticantes poderia variar, existiria competições de freestyle (malabarismos com a bola), tiros livres e de enterradas.

O documentário (DOIN' IT IN THE PARK, 2012), por sua vez, não aponta limitações para a prática do Streetball, indicando que não seria necessário nem mesmo uma quadra para sua prática, assim como não seria necessária a presença de árbitros, treinadores e organizações envolvidas. Para os autores, assim como apontado por Silva e Correia (2008), há flexibilidade das regras, nesse caso variando de uma quadra para outra, nem sempre obedecendo às regras do Basquetebol, sendo que por vezes, "humilhar" o adversário e até mesmo entreter o público seria mais importante que pontuar. Segundo (DOIN' IT IN THE PARK, 2012), todos podem praticar o Streetball,

\footnotetext{
${ }^{11}$ Os últimos registros da LIIBRA no estado de SP e de sua etapa nacional no RJ datam do ano de 2013 (RAPHAEL, 2013). Em 2014, foi encontrado apenas um registro da competição, referente a um evento organizado pela CUFA Ceará (JACÓ, 2014), o que pode indicar que a CUFA tenha deixado de realizar a LIIBRA.

${ }^{12}$ Neste subcapitulo serão apresentadas características e elementos das práticas esportivas aqui abordadas, tendo como referência as obras de Athayde ([2008?]; [2011?]), Palmer (2004) e Oliveira Filho (2006), assim como consulta as Mix Tapes (vídeos) da And1 disponíveis em seu site oficial e canal no Youtube.
} 
independentemente do tamanho, sexo, classe social, idade ou etnia dos indivíduos, logo os locais onde existe essa prática seriam ambientes de inclusão, onde qualquer um poderia participar (DOIN' IT IN THE PARK, 2012). Nessa perspectiva, podemos considerar o local (quadra, ruas, parques, etc.) onde existe a prática do Streetball um espaço de lazer, que contribui para "reduzir as diferenças, as disparidades, os desequilíbrios culturais que privam algumas esferas sociais de tudo o que a cultura urbana poderia lhes proporcionar" (DUMAZEDIER, 2008, p.170).

O Basquete de Rua apresentado pela CUFA e praticado na LIIBRA possui regras formais, que o difere do "Streetball/Basquete de Rua" (tidos como sinônimo no Brasil na década de 1990), do Streetball e Basquetebol institucionalizado pela International Basketball Federation (FIBA), sendo as principais diferenças: o tamanho da quadra - recomenda-se que seja de 12 por 22 m; Pontuação - cestas e jogadas (moves e enterradas) que podem valer $1,2,3,4,5$ ou 6 pontos; Número de atletas -6 por equipe (4 titulares e 2 reservas) (ATHAYDE, [2011?]). Por se tratar de uma competição e possuir regras delimitadas, ao contrário do Streetball apresentado por Garcia e Couliau (2012), que possui regras flexíveis, o pontuar seria o objetivo principal de quem a prática, inclusive por meio de fintas as quais são atribuídas pontuações.

É importante destacar também alguns elementos e características que diferenciam essas práticas esportivas (Basquetebol, Streetball e Basquete de Rua), pois facilitam a compreensão de indivíduos que talvez não tenham tido contato com esses esportes anteriormente, além do que serviram de base para elaboração do roteiro de observação utilizado na pesquisa de campo.

Algumas das jogadas e fundamentos que serão apresentados a seguir, são comuns a prática do Basquetebol, Basquete de Rua e/ou Streetball, porém nem sempre 
seguem as regras estabelecidas pelas organizações que os institucionalizaram. Quanto às jogadas e fundamentos, destacamos:

- Drible: no Basquetebol é o ato de "bater bola", impulsionando-a contra o solo com uma das mãos sem infringir as regras da modalidade. No Basquete de Rua e Streetball também é o ato de "bater a bola" no chão, porém pode se utilizar outras partes do corpo para tal, como: joelhos; pés, cotovelos; entre outras;

- $\quad$ Enterrada - jogada na qual o jogador salta e coloca a bola dentro da cesta, tocando ou segurando o aro com as mãos. Nas competições da LIIBRA, essa jogada tem uma pontuação diferenciada, valem 2 pontos. No Basquetebol também valem 2 pontos, o mesmo que arremessos realizados na zona de 2 pontos (a frente da linha de 3 pontos), a diferença é que na LIIBRA esses arremessos representam 1 ponto, logo a enterrada vale o dobro de pontos;

- $\quad$ Ponte Aérea - quando um companheiro de equipe lança a bola para alto para que seu companheiro enterre, também consideramos ponte aérea quando o próprio jogador que detém a posse da bola a lança para o alto, na tabela, no solo, ou no caso especifico do Streetball e Basquete de Rua em outros equipamentos (ex. placar/cronometro, etc.) ou locais da quadra (ex. parede lateral, pilastra da tabela, etc.) de forma que a bola ganhe altura e/ou volte na direção do próprio atleta que a lançou, permitindo que ele mesmo a enterre. Ponte aéreas finalizadas com enterrada valem 3 pontos nas competições da LIIBRA, no Basquetebol tem o mesmo valor que arremessos realizados a frente da linha de três pontos, ou seja, vale 2 pontos, assim como as enterradas;

- Move - movimento realizado com o intuito de ludibriar o adversário, pode ser realizado com auxílio de implementos (camiseta, testeira, entre outros), muitas 
vezes violam as regras do Basquetebol ao serem executados, abaixo destacamos alguns deles:

- Apagão - cobrir a cabeça do adversário com a camisa dele, ou com sua própria camisa. No Basquete de Rua institucionalizado pela LIIBRA é atribuído 1 ponto para realização desse move;

- Head Pop - quando o jogador de posse da bola a lança na cabeça do adversário, geralmente de forma que a bola volte para sua mão;

- Boomerang - o jogador lança a bola por cima do adversário de forma que essa retorne para si. Há movimentos similares a esse, onde a bola é lançada para o alto de diferentes formas (por trás do adversário, ao lado, entre outras), usando uma ou duas mãos, tendo efeito similar ao boomerang, onde o defensor perde a bola de vista, enquanto esse a procura, o atacante a pega de volta;

- Caneta - quando o jogador passa a bola por entre as pernas do adversário, no Streetball e Basquete de Rua pode ser realizada de diversas maneiras, inclusive utilizando auxílio dos pés e outras partes do corpo. Na LIIBRA é atribuído 1 ponto para realização desse move;

- Crossover - de posse da bola o jogador executa uma mudança de direção, geralmente driblando a bola de uma mão para outra, tirando o adversário da jogada;

- Freestyle - manipulação e controle da bola com ou sem auxílio de outros implementos (caneta, boné, etc.), com mais de uma bola e/ou utilizando diferentes partes do corpo (cabeça, costa, pés, braços, dedos, etc.). Também podem ser utilizados para compor moves. 
Abaixo destacamos o que consideramos ser elementos presentes no Basquete de Rua e Streetball, que podem ser encontrados também no movimento Hip-Hop, ainda que nesse, esses elementos apresentem outros significados:

- $\quad$ Trash Talk - coisas que são ditas durante o jogo (de provocações a elogios), com intuito de motivar, desmotivar e/ou desconcentrar os praticantes. Essas provocações podem ocorrer também em batalhas de RAP;

- Disc Jockey $(D J)$ - é o responsável pela escolha das músicas que tocam durante as partidas, normalmente utilizando Pick Up's;

- $\quad$ Mestre de Cerimônia (MC) - tem a função de entreter o público durante a partida, por vezes é o responsável por instigar os praticantes a se desafiarem em quadra por meio freestyles, moves, fintas, entre outras jogadas. Também pode intervir para manter o equilíbrio (acalmar os ânimos) dos praticantes durante as partidas;

- $\quad$ Música - as Mix Tapes e competições geralmente são acompanhadas de música, na maioria das vezes prevalecendo o $R A P$;

- Graffiti - elemento do movimento Hip-Hop, comum nos locais onde ocorre a prática do Streetball e Basquete de Rua. Encontram-se no entorno da quadra (em telas, painéis, paredes, etc.) e/ou na própria quadra (no chão, nas tabelas, etc.). Em eventos podem ser desenhados/feitos antes ou mesmo durante às partidas.

\section{Materiais e Métodos}

Esta é uma pesquisa qualitativa de caráter descritivo, realizada em três etapas, sendo elas:

$1^{\text {o }} \quad$ Etapa. Pesquisa bibliográfica e documental - realizada principalmente em três sistemas de buscas: Sistema Integrado de Bibliotecas Universidade de São 
Paulo (SIBiUSP); Sistema de Bibliotecas da Unicamp (SBU); Hemeroteca Digital. Tendo como palavras- chaves para a busca os termos: "streetball", "basquetebol" e "basquete de rua". As buscas realizadas na Hemeroteca Digital foram feitas com o objetivo de identificar as primeiras menções referente aos termos "streetball" e "basquete de rua" no Brasil.

Também foram materiais de consulta: livros, revistas, e documentários, além de websites voltados as práticas esportivas alvo ou correlacionadas com a pesquisa, que pudessem agregar novos conhecimentos a respeito do objeto de pesquisa;

$2^{\circ}$. Etapa. Pesquisa de campo - realizada em 2016 por meio de observação sistemática, individual, não participante, na vida real (MARKONI; LAKATOS, 2003), buscando assim observar a prática do Basquete de Rua em ambiente real, registrando os dados à medida que ocorriam, sem influenciá-los.

Os locais para coleta de dados foram definidos a partir de pesquisa via internet por municípios da Região Metropolitana de Campinas (RMC) que apresentassem histórico de praticantes e/ou equipes de Basquete de Rua e/ou Streetball, assim como de eventos voltados a estas práticas esportivas. Definidos os municípios (Sumaré, Campinas e Cosmópolis), foram selecionadas (via internet - sites, grupos nas redes sociais, blogs, etc.) quadras que atendessem aos seguintes critérios: ser de pública e/ou de livre acesso; apresentar histórico de eventos de Streetball e/ou Basquete de Rua; ou ser local onde a pratica do Basquetebol é reconhecidamente popular. Assim foram selecionadas cinco quadras, distribuídas da seguinte maneira: 
Tabela 1: Distribuição das quadras observadas

\begin{tabular}{ccc}
\hline QUADRA & CIDADE & ÁREA/REGIÃO DA CIDADE \\
\hline Quadra 1 (Q1) & Campinas & Área nobre \\
Quadra 2 (Q2) & Campinas & Região Central \\
Quadra 3 (Q3) & Sumaré & Região Central \\
Quadra 4 (Q4) & Sumaré & Periferia \\
Quadra 5 (Q5) & Cosmópolis & Periferia \\
\hline
\end{tabular}

Dessas quadras e locais destacamos algumas características:

- $\quad$ O local onde se encontra a Q1 possui três quadras próprias para a prática do Basquetebol, no entanto apenas uma estava em plenas condições de uso, por esse motivo focamos a observação nessa. A quadra possui características similares à do Basquetebol institucionalizado pela FIBA, possuindo dois aros e tabelas, marcações na quadra (linhas laterais, de fundo, 2 e 3 pontos, etc.);

- $\quad$ A Q2 possui dimensão aproximada de uma meia quadra de Basquetebol, possuindo apenas um aro (a uma altura visivelmente mais baixa) e uma tabela, nota-se também que as linhas/marcações no solo não condizem com os oficiais (destaque para o formato diferente do garrafão), além dessa quadra ser cercada por tela de alambrado, formando um tipo de "gaiola";

- $\quad$ Q3 e Q4 são quadras poliesportivas de escolas, tendo características que possibilitam a pratica do jogo em quadra inteira, no entanto Q4 não possui marcações que delimitam a área de 3 pontos e o garrafão tem formato diferente do oficial do Basquetebol;

- $\quad$ Q5 possui dimensão visivelmente menor que uma quadra ou meia quadra de Basquetebol, possuindo apenas um aro e tabela, suas linhas/marcações no solo também não condizem com as da modalidade. 
As coletas de dados foram realizadas duas vezes (2 dias) em cada local préestabelecido, tendo como duração mínima pré-estabelecida 2 horas diárias em cada local, a contar do horário de chegada do pesquisador a quadra e/ou a partir do momento de início da pratica. A mesma foi pautada em roteiro de observação que considerou as regras e normas estabelecidas pela Liga Internacional de Basquete de Rua (LIIBRA) referente ao Basquete de Rua (ATHAYDE, [2011?]), da FIBA referente ao Basquetebol $^{13}$ e também a descrição do Streetball no (DOIN' IT IN THE PARK, 2012).

$3^{\text {a }}$. Etapa. Análise dos dados - os dados foram analisados por meio da técnica de análise de conteúdo proposta por Laurence Bardin (2011).

\section{Resultado e Discussão}

\section{Pesquisa de campo}

Para realização da pesquisa de campo consideramos as jogadas e elementos do Basquete de Rua e Streetball apresentados anteriormente, as regras e normas estabelecidas pela LIIBRA, às regras e normas estabelecidas pela FIBA referente a prática do Basquetebol, e à caracterização do Streetball apresentada Garcia e Couliau (2012), o que nos permitiu buscamos identificar de que forma ocorre a prática do Basquetebol nas quadras públicas e/ou de livre acesso da RMC.

Na Tabela 2 destacamos a quantidade de praticantes ${ }^{14}$ observados durante as 78 partidas de acordo com o dia, local e gênero:

\footnotetext{
${ }^{13}$ No presente artigo apesar de considerarmos as regras do Basquetebol não as apresentamos, partimos do pressuposto de que suas regras são conhecidas por grande parte da população, devido a sua popularidade, presença em diferentes mídias, além de ser uma modalidade trabalhada nas escolas e outros contextos. No entanto, para aqueles que não as conheçam, as regras básicas da modalidade, assim como as regras completas, podem ser consultadas no site da FIBA, respectivamente nos links: http://www.fiba.basketball/basic-rules e http://www.fiba.basketball/basketball-rules.

14 Não somamos os números de praticantes dos dois dias de observação, pois não representaria a quantidade real do número de praticantes, já que a muitos dos praticantes estavam presentes nos dois dias
} 
Tabela 2: Quantidade de praticantes por gênero e total de praticantes observados nos dias de coleta dedados.

\begin{tabular}{cccccccc}
\hline QUADRA & $\begin{array}{c}\text { PRATICANTES } \\
\text { (sexo masculino) }\end{array}$ & \multicolumn{2}{c}{$\begin{array}{c}\text { PRATICANTES } \\
\text { feminino) }\end{array}$} & (sexo & \multicolumn{2}{c}{$\begin{array}{c}\text { TOTAL DE } \\
\text { PRATICANTES }\end{array}$} \\
\hline DIAS DE COLETA & $\mathbf{1}^{\mathbf{0}}$ DIA & $\mathbf{2}^{\mathbf{0}}$ DIA & $\mathbf{1}^{\mathbf{0}}$ DIA & $\mathbf{2}^{\mathbf{0}}$ DIA & $\mathbf{1}^{\mathbf{0}}$ DIA & $\mathbf{2}^{\mathbf{0}}$ DIA \\
\hline Quadra 1 (Q1) & 22 & 18 & 0 & 0 & 22 & 18 \\
Quadra 2 (Q2) & 6 & 8 & 0 & 0 & 6 & 8 \\
Quadra 3 (Q3) & 16 & 21 & 0 & 0 & 16 & 21 \\
Quadra 4 (Q4) & 20 & 16 & 1 & 1 & 21 & 17 \\
Quadra 5 (Q5) & 7 & 6 & 0 & 0 & 7 & 6 \\
\hline Total (Q1+Q2+Q3+Q4+Q5) & 71 & 69 & 1 & 1 & 72 & 70 \\
\hline
\end{tabular}

Nota-se que houve a presença de apenas uma praticante do sexo feminino, isso pode indicar que na RMC, ocorra o mesmo que ocorre no RJ e Porto Alegre, onde como apontado por Goellner et al. (2010), as mulheres além do trabalho, têm suas vidas atreladas a família e ao lar, o que não ocorre com os homens, que após o trabalho tem mais tempo para se dedicar a outras atividades, evidenciando assim diferenças de oportunidades entre homens e mulheres para realizar atividades de lazer.

A tabela abaixo destaca a quantidade de partidas observadas em cada dia de coleta de dados e qual tipo de jogo predominou: jogo de quadra inteira (utilizando 2 tabelas em quadra de dimensão similar à do Basquetebol) ou jogo de "meia quadra" (utilizando apenas uma tabela e metade da quadra ou em quadra que possuísse dimensão menor e apenas um aro e tabela):

de coletas de dados, ou seja, a soma poderia considerar um mesmo individuo 2 vezes, como é o caso da praticante do sexo feminino, que aparece em 2 dias, mas trata-se da mesma pessoa. 
Tabela 3: Quantidade e tipos de partidas realizadas em quadra inteira e meia quadra.

\begin{tabular}{|c|c|c|c|}
\hline QUADRA & $\begin{array}{c}\text { DIA } 1 \\
\text { (no de partidas) }\end{array}$ & $\begin{array}{c}\text { DIA } 2 \\
\left(n^{0} \text { de partidas) }\right.\end{array}$ & TOTAL DE PARTIDAS \\
\hline Quadra $1(\mathrm{Q} 1)$ & 8 - Meia quadra & 9 - Meia quadra & 17 partidas \\
\hline Quadra 2 (Q2) & 6 - Meia quadra & 7 - Meia quadra & 13 partidas \\
\hline Quadra 3 (Q3) & $\begin{array}{l}3 \text { - Meia quadra } \\
4 \text { - Quadra inteira }\end{array}$ & 11- Quadra inteira & 18 partidas \\
\hline Quadra 4 (Q4) & 9 - Quadra inteira & $\begin{array}{l}4 \text { - Meia quadra } \\
6 \text { - Quadra inteira }\end{array}$ & 19 partidas \\
\hline Quadra 5 (Q5) & 6 - Meia quadra & 5 - Meia quadra & 11 partidas \\
\hline Total $(\mathrm{Q} 1+\mathrm{Q} 2+\mathrm{Q3}+\mathrm{Q} 4+\mathrm{Q} 5)$ & 36 partidas & 42 partidas & 78 partidas \\
\hline
\end{tabular}

Em Q2 e Q5, devido a suas características prevaleceu o jogo de meia quadra, nos formatos 3 contra 3 ( 3 praticantes por equipe). No entanto, no primeiro dia de coleta de dados na Q2 pudemos observar também partidas de 1 contra 1, isto se deu até que chegassem pessoas suficientes para formar equipes compostas por trios, a partir de então, não houve mais esse tipo de disputa.

Nas quadras Q3 e Q4 houveram partidas de 3 contra 3 em meia quadra até que houvessem praticantes suficientes para formar equipes de 5 jogadores, a partir deste momento o jogo de quadra inteira (5 contra 5) prevaleceu.

$\mathrm{Na} \mathrm{Q} 1$, apesar da quadra possuir características similares as quadras oficiais de Basquetebol, e ser especifica para sua prática, mesmo com número suficiente de pessoas, não houve partidas de quadra inteira (5 contra 5), foram utilizadas duas metades da quadra, por dois grupos de pessoas que disputaram partidas no formato 3 contra 3. 
Quanto às regras, variaram de local para local e até mesmo de momento para momento em um mesmo local, sendo que as que mais se destacaram: quantidade de praticantes por equipe - se adequava de acordo com as características da quadra e/ou quantidade de praticantes no local; valor da pontuação atribuída às cestas convertidas se alterava de acordo com o local e tipo de jogo (quadra inteira - 5 contra 5, meia quadra - 1 contra 1 ou 3 contra 3), por exemplo, em uma mesma quadras no jogo disputado por trios, as cestas valiam um (lance livre), dois e três pontos, como ocorre no Basquetebol institucionalizado pela FIBA, enquanto no jogo 5 contra 5 , os arremessos da zona de três pontos valiam dois pontos e da zona de dois pontos valia um ponto; término das partidas - as partidas se encerravam por tempo e/ou pontuação pré-determinada, variando de local para local e/ou de momento para momento de acordo com o tipo de jogo.

Outro ponto relevante é que por vezes um lance tido como infração no Basquetebol, como por exemplo, condução de bola e/ou duas saídas, ocorria durante a partida e essa seguia normalmente, outras vezes era marcada a infração e o jogo era paralisado. Não podemos afirmar o porquê disso, levantamos 3 hipóteses: a primeira é de que esses lances as vezes passam despercebidos; a segunda é de que os praticantes podem não conhecer muito bem as regras do jogo de Basquetebol, o que dificultaria ou impediria que identificassem algumas das infrações; a terceira é de que os praticantes considerem esses lances e jogadas normais em um contexto informal e muitas vezes deixem o jogo seguir para que as partidas se tornem mais dinâmicas e com poucas paralisações. 
Na Tabela 4, apresentamos os elementos e jogadas comuns a pratica do Basquete de Rua, Streetball, muitas das quais não são permitidas no Basquetebol institucionalizado pela FIBA:

Tabela 4: Elementos e jogadas comuns ao Basquete de Rua presentes nas quadras e partidas observadas nos dois dias de coleta de dados.

\begin{tabular}{ccccc}
\hline QUADRA & MÚSICA & $\begin{array}{c}\text { MOVE } \\
\text { (Quantidade - Tipo) }\end{array}$ & TRASH TALK & ACESSÓRIOS \\
\hline Quadra 1 (Q1) & Não & $1^{15}$ & Sim & Boné \\
Quadra 2 (Q2) & Não & 2 (canetas) & Sim & Boné, Testeira, Camisa Térmica. \\
Quadra 3 (Q3) & Sim & 0 & Sim & Não houve \\
Quadra 4 (Q4) & Não & $1^{16}$ & & Bim \\
Quadra 5 (Q5) & Não & 2 (canetas) & Sim & Boné. \\
\hline
\end{tabular}

Nota-se que o move executado com mais frequência foi a "caneta", o que pode indicar a possível influência da LIIBRA fora do contexto competitivo, já que nessa competição tal movimento valia ponto. Outra possível explicação para que tal movimento tenha sido realizado com mais frequência, é a possibilidade de executa-lo sem infringir as regras do Basquetebol, o que aqui parece ser mais cabível, já que em nenhuma das partidas tal movimento ou qualquer outro move valeu ponto. Além disso, essa prevalência pode ser influência do futebol, o esporte mais praticado no Brasil (BRASIL, 2015) e que tem a "caneta" como um dos dribles populares.

\footnotetext{
${ }^{15} \mathrm{O}$ praticante jogou a bola na tabela de maneira que esta retornasse para si.

${ }^{16} \mathrm{O}$ praticante simulou que iria executar um "head pop", porém ao invés de lançar a bola na cabeça do adversário, ele a direcionou para o solo.
} 


\section{Considerações Finais}

Assim como ocorreu com o Streetball nos EUA (HORN 2014), não podemos afirmar onde teria surgido o Basquete de Rua no Brasil, no entanto, os dados encontrados, nos remetem ao ano de 1993 como sendo o ano do primeiro registro referente ao termo Basquete de Rua e/ou Streetball no país.

Nos anos 2000, influenciadas pela dimensão que o Streetball norte-americano ganhou no mundo, por meio principalmente de ações da AND1, ONG's passaram a desenvolver o Basquete de Rua no Brasil para atender a seus propósitos, nessa perspectiva, destacam-se a LUB e CUFA, sendo esta última responsável pela criação da LIIBRA, que trouxe uma nova forma de disputa, diferenciando em alguns aspectos a prática do Streetball/Basquete de Rua brasileiro da década 1990 da dos anos 2000, ao menos no que diz respeito ao contexto competitivo.

Quanto ao Basquetebol praticado nos espaços de lazer da RMC, como pudemos observar que não segue à risca as normas estabelecidas pela FIBA, e apresentaram ao menos um dos elementos e/ou jogadas características do Streetball e Basquete de Rua, no entanto, aparentemente também não seguindo as regras e normas estabelecidas pela CUFA em relação a essa prática no Brasil, mas sim regras próprias.

Por fim, se considerarmos as características (flexibilidade das regras - adaptadas de acordo com o número de praticantes e peculiaridades locais) e os elementos e jogadas observadas no Basquetebol praticado nos espaços de lazer da RMC, podemos compreender que nesses espaços ocorre a prática do Streetball, ou utilizando a adaptação brasileira do termo, Basquete de Rua, devido a sua similaridade com a prática norte-americana apresentada em (DOIN' IT IN THE PARK, 2012). Acreditamos ainda que essas características contribuem para que o Basquete de Rua como atividade de 
lazer propicie o convívio entre diferentes indivíduos, que podem nesta vivência se expressar cada um à sua maneira dentro do jogo.

\section{REFERÊNCIAS}

AND1. The MixTapes. Disponível em: http://and1.com/mixtape-page/ . Acesso em: 24 set. 2017.

ATHAYDE, C. Regras oficiais do basquete de rua do Brasil: Manual dos Basqueteiros 2008/2009. Rio de Janeiro: CUFA, [2008?]. Disponível em: https://cufasp.wordpress.com/regras . Acesso em: 20 set. 2017.

Manual Basquete de Rua. Rio de Janeiro: CUFA, [2011?].

BARDIN, L. Análise de conteúdo. Lisboa: Edições 70, 2011.

BASQUETE ganha a Rua na Barra. Jornal do Brasil, Rio de Janeiro, p.4, 31 de maio de 1993.

BRASIL. Ministério do Esporte. A pratica de esporte no Brasil. Brasília, 2015. Disponível em: http://www.esporte.gov.br/diesporte/2.html . Acesso em: 28 set. 2017.

CANAN, F. E.; SILVA, R. V. Considerações histórico-sociológicas acerca do basquete de rua e suas possíveis relações com a educação física escolar. Caderno de Educação Física e Esporte, Marechal Cândido Rondon, v. 11, n. 1, p. 65-77, jan./jun. 2013.

CONFEDERAÇÃO BRASILEIRA DE BASKETBALL. A História Oficial do Basquete. [20--?]. Disponível em: http://www.cbb.com.br/OBasquete/HistoriaOficial . Acesso em: 25 set. 2017.

DOIN' IT IN THE PARK: Pick-Up Basketball, New York City. New York. Direção de Bobbito Garcia e Kevin Couliau, 2012. Documentário. Disponível em: http://buy.doinitinthepark.com/ . Acesso em: 06 abr. 2015.

DUMAZEDIER, J. Sociologia empírica do lazer. 3. ed. São Paulo: Perspectiva, 2008.

ESPORTE hoje. Jornal do Brasil. Rio de Janeiro, p.16, 14 de maio de 1994.

FIBA. BASKETBALL. Rules Of the Game. 2017. Disponível em: http://www.fiba.basketball/basketball-rules . Acesso em: 10 set. 2017.

Basic Rules. 2017. Disponível em: http://www.fiba.basketball/basic-rules . Acesso em: 10 set. 2017.

FREITAS, A; VIEIRA, S. O que é basquete: história, regras, curiosidades. Rio de Janeiro: Casa da Palavra, 2006. 
FUNDAÇÃO BIBLIOTECA NACIONAL. Hemeroteca Digital. 2017. Disponível em: http://bndigital.bn.br/hemeroteca-digital/ . Acesso em: 28 set. 2017.

GALATTI, L.R. Pedagogia do Esporte: O livro didático como um mediador no processo de ensino e aprendizagem dos jogos esportivos coletivos. (2006). 138f. Dissertação (Mestrado) - Faculdade de Educação Física, Universidade Estadual de Campinas. Campinas: [s.n], 2006.

GALATTI, L. R.; REVERDITO, R. S.; SCAGLIA, A. J.; PAES, R. R.; SEOANE, M. A. PEDAGOGIA DO ESPORTE: TENSÃO NA CIÊNCIA E O ENSINO DOS JOGOS ESPORTIVOS COLETIVOS. Revista da Educação Física.UEM, Maringá, v. 25, n. 1, p. 153-162, mar. 2014.

GOELLNER, S. V.; VOTRE, S. J.; MOURÃO, L.; FIGUEIRA, M. L. Lazer e Gênero nos Programas de Esporte e Lazer das Cidades. Licere (Centro de Estudos de Lazer e Recreação. Online), v. 13, p. 1, n. 2010.

HORN, L. The history behind Red Bull King of the Rock. 30 de ago. de 2014. Disponível em: http://www.redbull.com/en/stories/1331675240605/the-history-ofstreetball-and-red-bull-king-of-the-rock . Acesso em: 26 nov. 2015.

JACÓ BASQUETE DE RUA CEARÁ - BRASIL. Jogador profissional de basquete de rua, atua em campeonatos nacionais e internacionais e em eventos esportivos $e$ culturais como apresentações freestyle, desafios, clinicas e comerciais para TV.16 de novembro de 2014. Disponível em: http://jacoreidarua.blogspot.com.br/2014/11/ligainternacional-de-basquete-de-rua_16.html . Acesso em: 28 set. 2017.

LIGA URBANA DE STREetBALl. A história do Basquete de Rua. 2010. Disponível em: http://www.lusb.com.br/pagina.php?pag=3 . Acesso em: 28 abr. 2017.

MACHADO, G.V; GALATTI, L.R.; PAES, R. R. Seleção de conteúdos e procedimentos pedagógicos para o ensino do esporte em projetos sociais: reflexões a partir dos jogos esportivos coletivos. Motrivivência, Florianópolis, v. 39, p. 164-176, 2012.

MACHADO G. V.; GALATTI, L. R.; PAES R. R. Pedagogia do esporte e o referencial histórico-cultural: Interlocução entre teoria e prática. Revista Pensar a Prática, Goiânia, v. 17, n. 2, p. 414-430, 2014.

MARCELLINO, N. C. Lazer e qualidade de vida. In: MOREIRA, W. W. (Org.). Qualidade de vida: complexidade e educação. 2. ed. Campinas: Papirus, 2007

MARCONI, M. A.; LAKATOS, E. M. Fundamentos de metodologia científica. 5. ed. São Paulo: Atlas, 2003.

OLIVEIRA FILHO, A. História do Basquete de Rua. Rio de Janeiro, dezembro, 2006. Disponível em: http://www.lub.org.br/lub/?page_id=13 . Acesso em: 05 maio 2014.

PALMER, C. Streetball: all the ballers, moves, slams and shine, New York: Harper Collins, 2004. 
PIZANI, R. ; AMARAL, S. C. F. ; PAES, R. R. . Esporte e Lazer: Diálogos Possíveis à Luz da Pedagogia do Esporte. Licere. Belo Horizonte v. 15, p. 1-18, 2012.

RAPHAEL, CLAUDIA. Cufa Sorocaba Recebe Homenagem Pelo Vice-Campeonato Da LIIBRA 2013. 26 de fev. de 2014. Disponível em: http://cufasp.org.br/cufasorocaba-recebe-homenagem-pelo-vice-campeonato-da-liibra-2013/ . Acesso em: 15 out. 2015.

REIS DA RUA. Reis da Rua 2010. Disponível em: http://www.reisdarua.com.br/in.php?id=reisdarua. Acesso em: 06 abr. 2015.

SILVA, C. A. F.; CORREIA, A. M. Espetáculo e reflexividade: a dimensão estética do basquete de rua. Revista Brasileira de Ciências do Esporte, Campinas, v. 30, n. 1, p. 107-122, 2008.

ZAMBELLI, T. História do basquetebol nas quadras externas de Campinas/SP: $\mathrm{O}$ diálogo do Streetball, 2004. 97f. Trabalho de Conclusão de Curso (Graduação em Educação Física) Faculdade de Educação Física, Universidade Estadual de Campinas, Campinas, 2004.

\section{Endereço dos Autores:}

Douglas Vinicius C. Brasil

Cidade Universitária "Zeferino Vaz"

Av. Érico Veríssimo, 701 - Barão Geraldo

Campinas - SP - 13.083-851

Endereço Eletrônico: douglasviniciuscarvalhobrasil@gmail.com

Thiago José Leonardi

Rua Felizardo, no 750 - Jardim Botânico

Porto Alegre - RS - 90.690-200

Endereço Eletrônico: thiago_leonardi@yahoo.com.br

Alcides José Scaglia

Faculdade de Ciências Aplicadas da Unicamp

R. Pedro Zaccaria, 1300

Limeira - SP - 13.484-350

Endereço Eletrônico: alcides.scaglia@gmail.com

Roberto Rodrigues Paes

Cidade Universitária "Zeferino Vaz"

Av. Érico Veríssimo, 701 - Barão Geraldo

Campinas - SP - 13.083-851

Endereço Eletrônico: robertopaes@fef.unicamp.br 